\title{
Immunohistology of rheumatoid nodules and rheumatoid synovium
}

\author{
N A ATHANASOU, ${ }^{1}$ J QUINN ${ }^{1}$ C G WOODS ${ }^{2}$ AND J O'D McGEE
}

From the ${ }^{1}$ Nuffield Department of Pathology, University of Oxford, John Radcliffe Hospital, Oxford; and the $\rightarrow$ ${ }^{2}$ Nuffield Orthopaedic Centre, Oxford

SUMMARY The immunohistological features of rheumatoid nodules and rheumatoid synovium

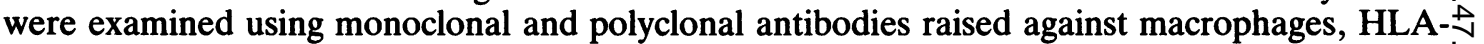
DR, leucocyte common antigen, and immunoglobulin components. The palisading cellsir surrounding the necrotic centre of the rheumatoid nodule were shown to be HLA-DR positive $\omega_{\infty}$ leucocytes, mostly histiocytes. The inflammatory infiltrate associated with rheumatoid noduleso showed many immunohistochemical similarities to that of rheumatoid synovium, including a preponderance of IgG positive plasma cells, and a similar number and microanatomical pattern 3 of distribution of HLA-DR positive cells. The significance of these findings for the cellular₹ immunopathology and aetiology of the rheumatoid lesion is discussed.

Key words: rheumatoid arthritis, immunohistochemistry, monoclonal antibody.

Rheumatoid nodules (RNs) are the most characteristic single histopathological lesion associated with rheumatoid arthritis (RA). ${ }^{12}$ They are particularly associated with seropositive RA and have been found in the synovium of $7 \cdot 6 \%$ cases of seropositive RA. ${ }^{1}$ They have also been described in many extra-articular locations, being most commonly found in the subcutaneous tissue overlying bony prominences. $^{23}$ Histologically, RNs consist of a central irregular area of necrosis rimmed by a palisade of radially arranged, elongated cells, which are themselves surrounded by highly vascularised connective tissue containing a chronic inflammatory infiltrate. $^{23}$

The pathogenesis of $\mathrm{RN}$ formation and the relation of this granulomatous reaction to the inflammation and occasional necrosis seen in rheumatoid synovium (RA synovium) is unknown. ${ }^{1-3}$ Even the nature of cells present in the inflammatory reaction associated with RNs is uncertain. In particular, the elongated cells which form a corona around the central necrotic zone of the RN have been variously classified on the basis of histochemical, immunohistochemical, and ultra-

Accepted for publication 11 November 1987.

Correspondence to Dr N A Athanasou, Nuffield Department of Pathology, University of Oxford, John Radcliffe Hospital, Oxford OX3 9DU.

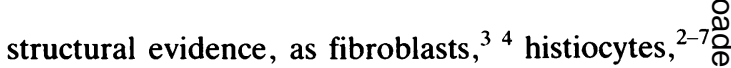
or proliferating vascular parietal cells or angio- $\frac{\Omega}{2}$ blasts. $^{3}$

In this study we examined the cellular immunopathology of RNs and compared these findings with those found in RA synovium. We used immunohistochemical techniques with monoclonal and polyclonal antibodies directed against leucocytes, including several antimacrophage markers. Our 3 findings showed that almost all the palisading cellsi of RNs are leucocytes, mostly histiocytes. We also found several interesting immunohistological ${ }_{0}$ similarities between RNs and RA synovium.

\section{Materials and methods}

Formalin fixed, paraffin embedded blocks of cases of RA synovium and RNs were retrieved from the files of the John Radcliffe Hospital and the Nuffieldw Orthopaedic Centre. These included samples of synovial membrane obtained at synovectomy of joint replacement from 13 patients with seropositived RA and biopsy specimens of RNs from 12 patients with seropositive RA. Five of the RNs were located? around the elbow, five around the thumb or fingers $\frac{O}{\mathbb{D}}$ and two in RA affected synovium. In these last two? specimens the immunohistochemical features of both the inflamed synovium and the RNs were independently assessed. 
Table 1 Monoclonal and polyclonal ${ }^{*}$ antibodies used in the present study

\begin{tabular}{llcl}
\hline & Source & $\begin{array}{c}\text { Reference } \\
\text { No }\end{array}$ & Antigen/cell specificity \\
\hline PD7/26 & D Y Mason & 9 & Leucocyte common antigen \\
2B11 & D Y Mason & 10 & Leucocyte common antigen \\
CR3/43 & D Y Mason & 11 & HLA-DR \\
Mac 387 & D Y Mason & 12 & Macrophages, some granulocytes \\
Anti- $\alpha_{1}$ antitrypsin* & Behring & 13 & $\alpha_{1}$ Antitrypsin: macrophages, granulocytes \\
Antilysozyme* & Behring & 14 & Lysozyme: macrophages, granulocytes, \\
Anti-immunoglobulin (Ig) & some epithelial cells \\
Heavy chain & Dako (UK) & & IgG, IgM, IgA \\
Light chain & & & $x, \lambda$ \\
\hline
\end{tabular}

\section{IMMUNOHISTOCHEMISTRY AND}

EXAMINATION OF HISTOLOGICAL SECTIONS Serial $5 \mu \mathrm{m}$ sections were mounted on Multispot slides (Hendley, Essex). These were stained by an indirect immunoperoxidase technique as previously described. ${ }^{8}$ Negative control sections consisted of the additions of trometamol (TRIS) buffer alone without primary antibody. Table 1 shows the monoclonal and polyclonal antibodies used in this study. Sections were digested for 30 minutes by $0 \cdot 1 \%$ trypsin (Sigma, T: 8128 ) in $0.1 \%$ calcium chloride at $\mathrm{pH} \mathbf{7 . 8}$ before immunostaining with CR3/43, anti-heavy and light chain immunoglobulin, and Mac 387.

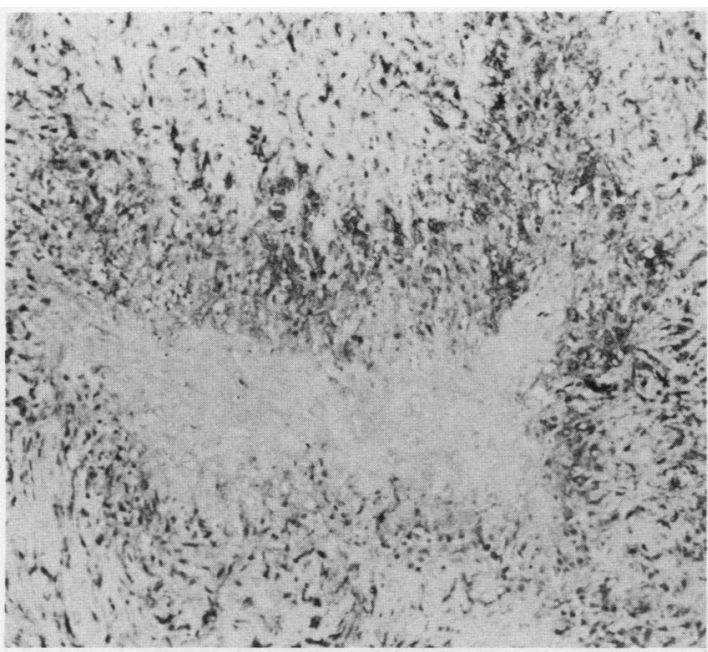

Fig. 1a

Fig. 1 Immunoperoxidase staining of $R N$ with $P D 7 / 26$ for leucocyte common antigen ( $L C A)$. (a) RN surrounded by $L C A$ positive palisading cells. There is an intense inflammatory infiltrate surrounding the nodule. (b) Higher magnification of Fig. 1a with membrane staining of palisading cells around the necrotic centre (left). (c) Giant cell amongst the palisading cells of an $R N$ with membrane staining for $L C A$.

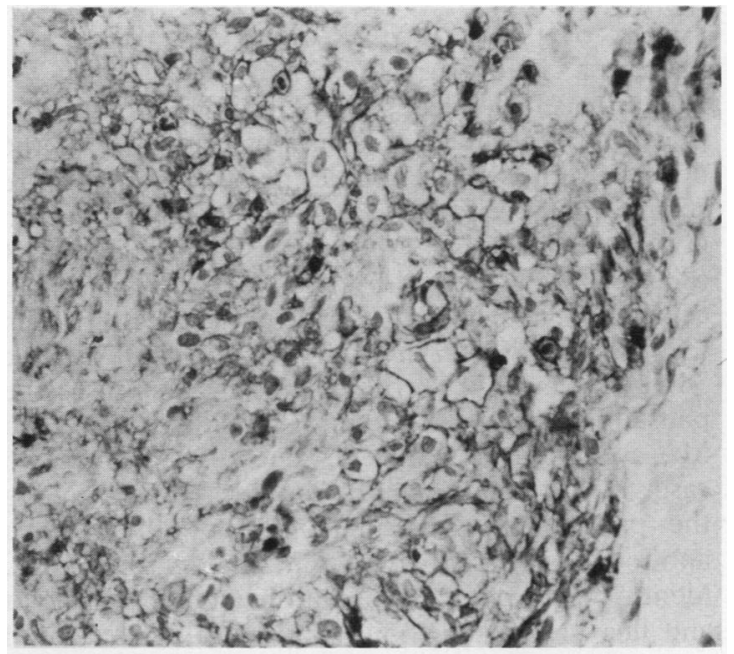

Fig. 1b

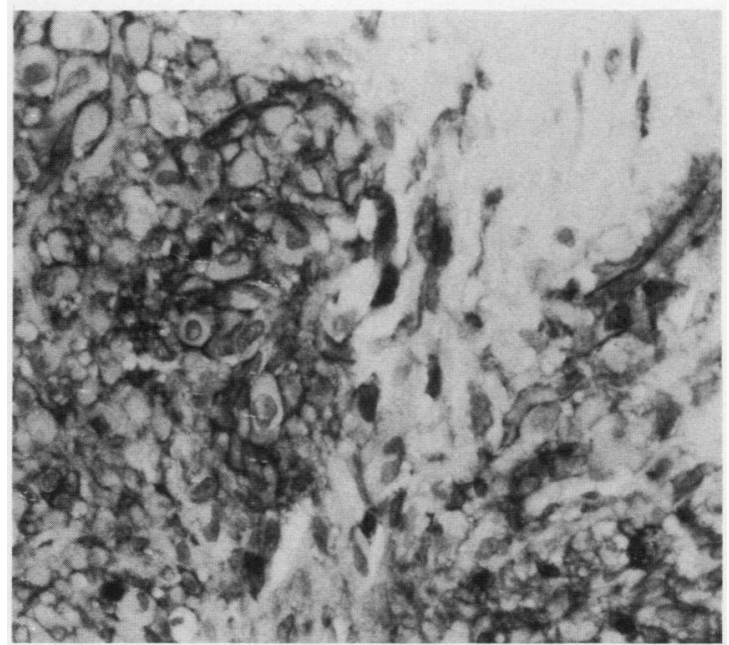

Fig. 1c 
The percentage of cells reported to react with a particular monoclonal or polyclonal antibody was evaluated after counting 300 palisading cells and 300 synovial lining cells in serial sections of RNs and RA synovium respectively. The same area of each serial section was also assessed with an eyepiece graticule to reduce errors due to differences in sampling and differences related to the degree of inflammation and age of the lesion. The relative proportions of IgG and IgM reacting cells in RNs and RA synovium were similarly assessed after counting $\mathbf{5 0}$ light chain positive cells.

\section{Results}

IMMUNOHISTOLOGY OF RHEUMATOID NODULES (RNs)

Immunohistochemical staining of RNs showed that most of the cells which form a palisade around the necrotic centre of the nodule (palisading cells) were strongly positive for both leucocyte common antigen (LCA) (87-96\%) (Figs $1 \mathrm{a}$ and b) and HLA-DR (80-95\%) (Figs 2a and b). Most of these palisading cells were also strongly positive for $\alpha_{1}$ antitrypsin $(32-60 \%)$ and lysozyme $(37-56 \%)$ as well as Mac 387 positive $(62-84 \%)$ (Fig. 3 ). In most cases the palisading cells that stained for LCA, lysozyme, and Mac 387 were mononuclear leucocytes, but in two cases identifiable polymorphs were present among the palisading cells and stained by these three antibodies. In all cases scattered plasma cells, identified morphologically and by staining for light and heavy immunoglobin chains, were also found among the palisading cells. Plasma cells and other mononuclear cells containing immunoglobulin were

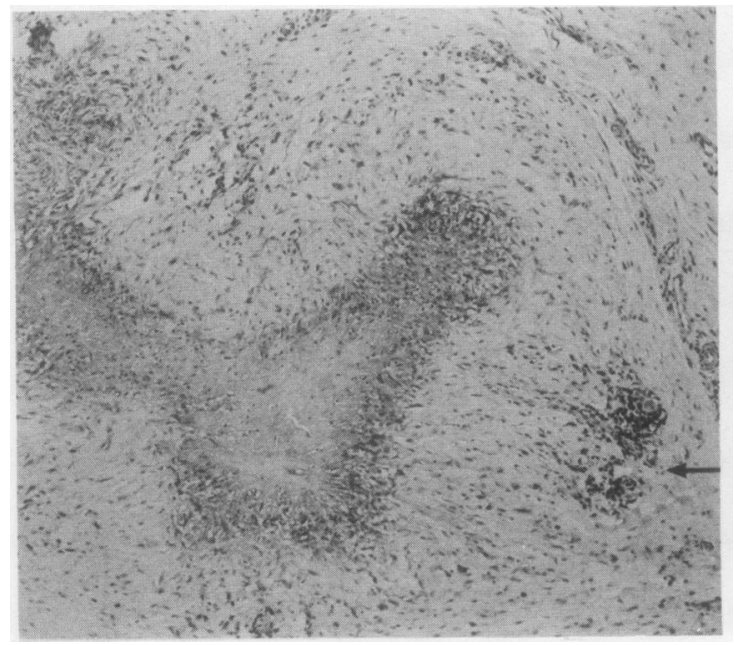

Fig. 2a

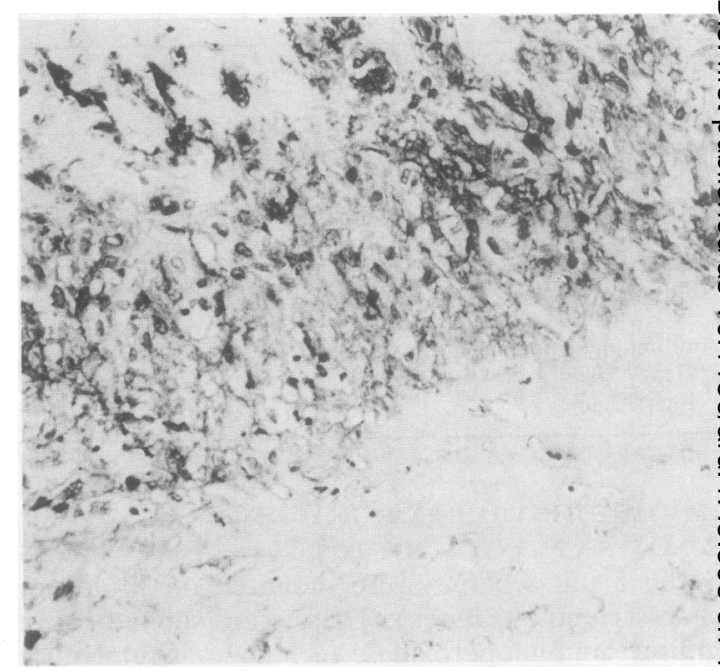

Fig. 2b

Fig. 2 Immunoperoxidase staining of $R N$ with $C R 3 / 43$ (anti-HLA-DR). (a) $R N$ with $H L A-D R$ positive palisading cells and $H L A-D R$ positive mononuclear cells disposed around a small blood vessel (arrow). (b) Higher magnification of Fig. $2 a$ with HLA-DR positive staining of palisading cells around necrotic centre.

clearly a minority (less than $5 \%$ ) of the populatio of the palisading cells and were most prominent $a \mathrm{p}^{\circ}$ the margins of the RN. There were more $\operatorname{IgC}$ $(56-86 \%)$ than IgM $(4-38 \%)$ or IgA $(4-28 \% 尹$ reacting cells in the palisade layer. Giant cells were also present among the palisading cells of severas. RNs. These strongly reacted for LCA (Fig. 1c) and

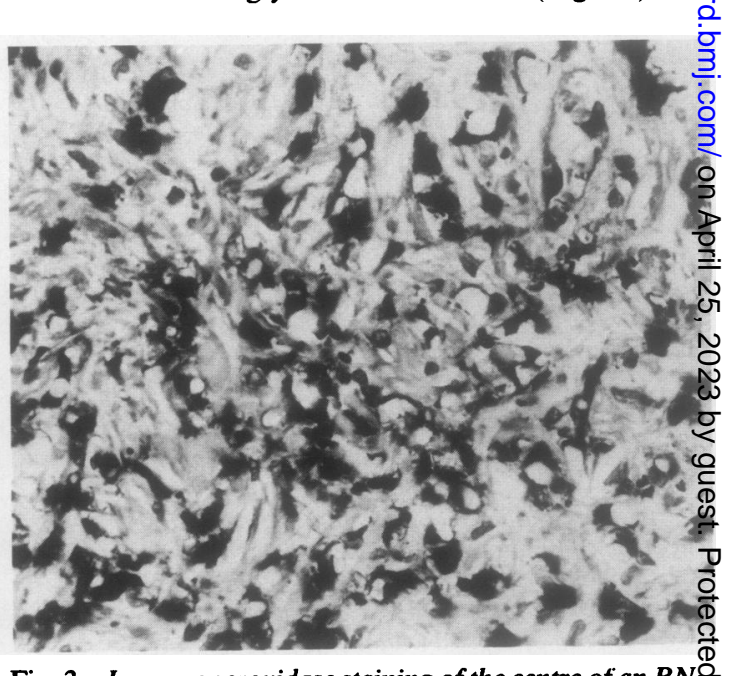

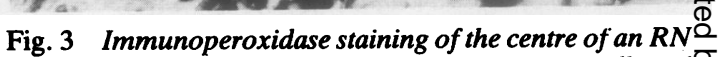
showing strong cytoplasmic staining of palisading cells witk Mac 387 (antimacrophage). 
HLA-DR, and many were also Mac 387 positive. There were abundant HLA-DR (72-87\%) positive mononuclear leucocytes (LCA positive) in the inflammatory infiltrate present in the loose connective tissue surrounding the RN. These HLA-DR positive cells were histiocyte-like cells of irregular, round or spindle-shaped outline with a vesicular nucleus. HLA-DR positive cells were also present around small and large blood vessels (Fig. 2a). Many, but not all, of the HLA-DR positive mononuclear cells in the inflammatory infiltrate were also strongly positive with Mac 387 (54-86\%), and weakly positive with anti- $\alpha_{1}$ antitrypsin (37-64\%) and antilysozyme (35-55\%). In addition, occasional endothelial cells of small blood vessels were weakly HLA-DR positive. Immunoglobulin containing cells (mostly IgG positive) were also present in the inflamed connective tissue surrounding RNs.

\section{IMMUNOHISTOLOGY OF RHEUMATOID}

\section{SYNOVIUM}

The synovial intimal cells in rheumatoid synovium reacted strongly for LCA (88-97\%) and HLA-DR $(90-95 \%)$ (Fig. 4a) and were strongly Mac 387 $(67-86 \%)$ positive. In synovium where the intimal cells were of normal thickness (one or two cell layers) or greatly thickened and hyperplastic (more than two cell layers) these antibodies produced almost uniform staining of synovial lining cells. These cells reacted weakly and less consistently with $\alpha_{1}$ antitrypsin (22-32\%) and lysozyme (21-25\%).

There was a heavy, largely mononuclear cell inflammatory infiltrate in the loose subintimal synovial stromal connective tissue. These cells stained strongly for LCA, and many (83-90\%) were also positive for HLA-DR. In addition, in serial sections, $57-74 \%$ of these cells also stained with Mac 387, and $46-80 \%$ for $\alpha_{1}$ antitrypsin and lysozyme. The HLA-DR positive cells were disposed around large and small blood vessels in a similar fashion to that seen in $\mathrm{RN}$ biopsy specimens. In addition, occasional HLA-DR positive endothelial cells were seen. Staining for light and heavy chain immunoglobulin components confirmed that abundant plasma cells were present in the inflamed synovium. IgG reacting cells $(46-85 \%)$ outnumbered those reacting for $\operatorname{IgM}(6-44 \%)$ or $\operatorname{IgA}(4-32 \%)$.

Classical RNs and hemigranulomas (i.e., RNs opening onto the synovial surface), which were noted in synovial specimens from two patients, showed the same immunohistological features as RNs in subcutaneous tissue described above. Giant cells in the rheumatoid synovium, which were unassociated with classical RNs or hemigranulomas, showed a similar pattern of reactivity to that of synovial lining cells (Fig. 4b).

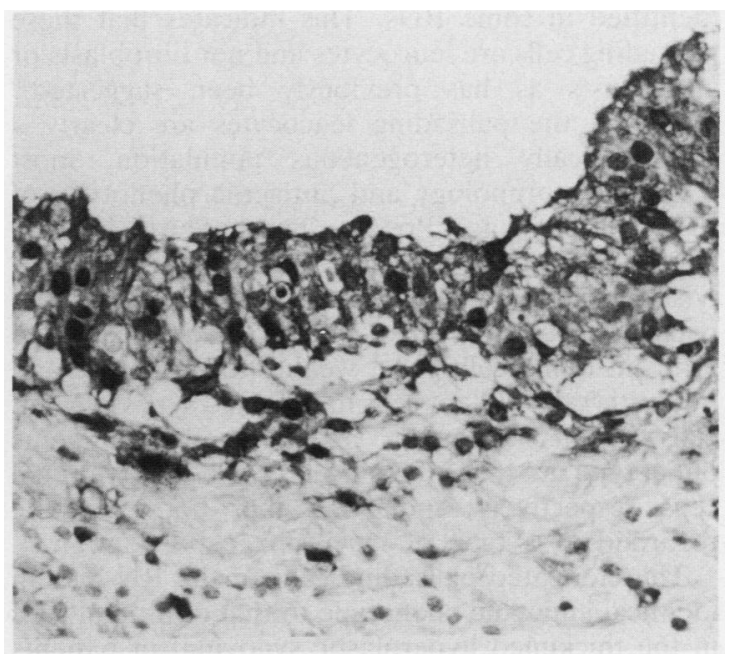

Fig. $4 \mathrm{a}$

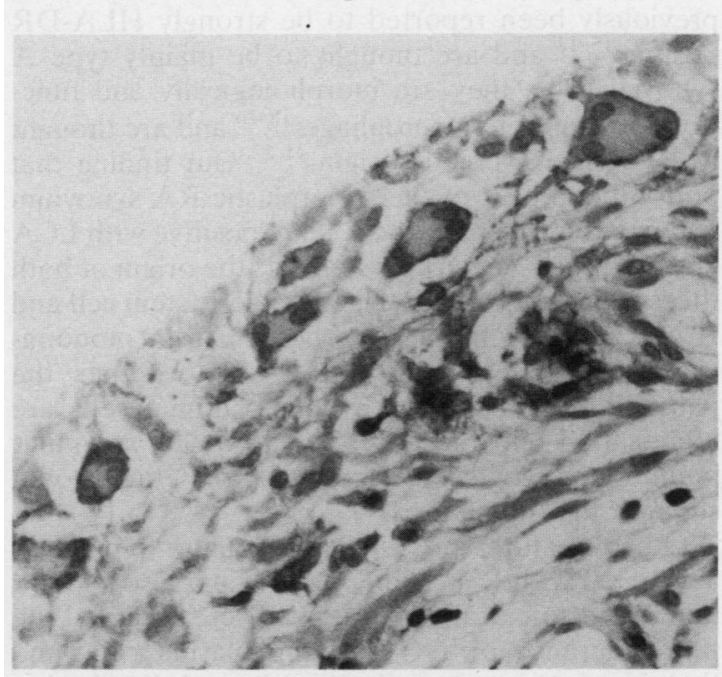

Fig. $4 \mathrm{~b}$

Fig. 4 (a) Immunoperoxidase staining of rheumatoid synovium with CR3/43 (anti-HLA-DR) showing strong staining of synovial intimal cells. (b) Immunoperoxidase staining of rheumatoid synovium with PD7/26 (anti-LCA) showing membrane staining of synovial giant cells.

\section{Discussion}

In this study we showed that the palisading mononuclear cells which form a corona around the necrotic centre of the $\mathrm{RN}$ are positive for LCA, HLA-DR, and several monocyte-macrophage markers (Mac 387, $\alpha_{1}$ antitrypsin, lysozyme). Cells containing immunoglobulin were also scattered among the palisading cells, particularly at the margin of the nodule, and polymorphs were also 
identified in some RNs. This indicates that these palisading cells are leucocytes and not fibroblasts or angioblasts as has previously been suggested. ${ }^{3}$ Although the palisading leucocytes are clearly a phenotypically heterogeneous population, most have the morphology and antigenic phenotype of tissue macrophages. Previous immunohistochemical studies have shown that large numbers of HLA-DR positive and macrophage-like cells are present in the palisade layer ${ }^{56}$ and that both palisading cells and synovial lining cells react weakly for lysozyme and $\alpha_{1}$ antitrypsin. ${ }^{7}$ Giant cells in RNs and synovial giant cells in RA synovium had a similar antigenic phenotype to that of palisading cells and intimal cells respectively, indicating that both may be regarded as a type of macrophage polykaryon.

The elongated palisading cells of the $\mathrm{RN}$ had an identical antigenic phenotype to that of intimal cells in the thickened hyperplastic synovium of patients with seropositive RA. These intimal cells have previously been reported to be strongly HLA-DR positive $^{15-17}$ and are thought to be mainly type A synovial cells; they are morphologically and functionally similar to macrophages ${ }^{18-20}$ and are thought to be of haemopoietic origin. ${ }^{21} 22$ Our finding that both intimal cells of the hyperplastic RA synovium and palisading cells of the RN are positive with LCA and macrophage markers supports the origin of both these cell types from the haemopoietic stem cell and is in keeping with their derivation from mononuclear phagocytes. It is not certain whether the palisading cells and the synovial intimal cells are identical. Their presence, however, in a similar immunopathological background (see below) would support this hypothesis.

Other features of the inflammatory reaction associated with RNs and RA synovium also showed immunohistological similarities. These included the preponderance of IgG reacting plasma cells and the abundance and similar histological distribution of HLA-DR positive cells in the inflammatory infiltrate of both lesions. ${ }^{23}$ HLA-DR is strongly expressed by several cell types that are known to be involved in antigen presentation and processing, including $\mathrm{B}$ cells, activated $\mathrm{T}$ cells, interdigitating reticulum cells, and macrophages. ${ }^{24}$ The immunohistological analysis of RNs by Duke et al showed that in the inflammatory infiltrate around RNs there were only a minority of $\mathrm{T}$ cells $(0-30 \%)$ which were also HLA-DR positive ${ }^{6}$; $B$ cells and plasma cells were also a very minor component of the inflammatory infiltrate, a feature confirmed by this study. In combination with our results of staining of serial sections with Mac 387 , this strongly suggests that most HLA-DR positive cells in the inflammatory infiltrate are macrophages or interdigitating reticu- lum cells. Previous immunohistochemical studies of RA synovium have shown that the HLA-DR: reacting cells in RA synovium include both endothelial cells and a population of macrophage-like 0 dendritic cells which resemble interdigitating reticulum cells found in the paracortical $T$ cell areas $\frac{\bar{m}}{\bar{T}}$ of normal lymph nodes. ${ }^{162425}$ These synovial $\stackrel{\mathbb{\Omega}}{\Omega}$ dendritic cells were scattered around blood vessels where they are closely associated with $T$ helper cells, the predominant cell type found in RA. synovium. ${ }^{16} 2425 \mathrm{~T}$ cells are also the main lympho- $\overrightarrow{\vec{\omega}}$ cyte type in the inflammatory infiltrate around $\mathrm{RNs}, \stackrel{\omega}{\sigma}$ though the exact proportion of $\mathrm{T}$ cells of helper phenotype is not certain. ${ }^{56}$ The similar histological distribution of strongly staining HLA-DR positive cells around blood vessels and the weak HLA-DR staining of endothelial cells which we have noted in $\bigodot_{\infty}$ biopsy specimens of both RA synovium and RNs are $\mathrm{O}$ consistent with the above findings. It also suggests that many of the perivascular HLA-DR positive 3 cells found in RNs are identical to the dendritic cells found in RA synovium.

The range of monoclonal antibodies used in this study does not permit firm conclusions regarding the pathogenesis of RNs. In common with previous studies, ${ }^{5-7}$ we have noted only small amounts of immunoglobulin in these lesions and have found no evidence of immunoglobulin deposition in vessel walls, a feature which argues against vasculitis as a $\stackrel{\mathbb{Q}}{2}$ primary mechanism in RN formation. Our findings $\overrightarrow{\vec{O}}$ do suggest, however, that there are distinct similari- $\exists$ ties in the cellular immunopathology of both RNs and RA synovium. If this is true then a similar antigenic factor may be responsible for the pathological changes seen in both RNs and RA synovium. The reason why this antigenic factor leads to the formation of RNs in some but not all patients with seropositive RA may be accounted for by the variable host immune response which, in $R A$, is known to be strongly associated with genetic factors. ${ }^{26}$

This study was supported by the Arthritis and Rheumatism Council. We would like to thank Miss L Watts for typing the manuscript and Mr G Richardson and Ms J Pollitt for processing the photographs.

\section{References} Dick W C, Moll R J M H, eds. Recent advances in rheuma- $\mathbb{D}$

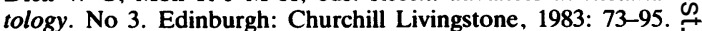

2 Gardner D L. Pathology of rheumatoid arthritis. In: Scott J T, $\square$ ed. Copeman's textbook of the rheumatic diseases. Edinburgh: Churchill Livingstone, 1986; 604-52.

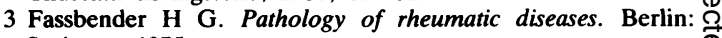
Springer, 1975.

4 Cochrane W, Davies D V, Dorling J, Bywaters E G L. Ultramicroscopic structure of the rheumatoid nodule. Ann Rheum Dis 1964; 23: 345-63. 
5 Hedfors E, Klareskog L, Lindblad S, Forsum U, Lindahl G. Phenotypic characterization of cells within subcutaneous rheumatoid nodules. Arthritis Rheum 1983; 26: 1333-9.

6 Duke O L, Hobbs S. Panayi G S, Poulter L W, Rasker J J. Janossy G. A combined immunohistological and histochemical analysis of lymphocyte and macrophage subpopulations in the rheumatoid nodule. Clin Exp Immunol. 1984; 56: 239-41.

7 Aherne M J, Bacon P A, Blake D R, et al. Immunohistochemical findings in rheumatoid nodules. Virchows Arch /A] 1985; 407: 191-202.

8 Gatter K C, Falini B, Mason D Y. The use of monoclonal antibodies in histopathological diagnosis. In: Anthony $\mathrm{P} P$, MacSween R N M, eds. Recent advances in histopathology. No 12. Edinburgh: Churchill Livingstone, 1984; 35-67.

9 Warnke R A. Gatter K C, Falini B, et al. Diagnosis of human lymphoma with monoclonal antileukocyte antibodies. $N$ Engl J Med 1983; 309: 1275-82.

10 Sanchez Madrid F, Nagy J A, Robbing E, Simon P, Springer T A. A human leucocyte differentiation antigen family with distinct alpha subunits and a common $\beta$ subunit. $J$ Exp Med 1983; 158: $1785-803$.

11 Gatter K C, Abdulaziz Z, Beverley P, et al. Use of monoclonal antibodies for the histopathological diagnosis of human malignancy. J Clin Pathol 1982; 35: 1253-67.

12 Jones D B, Flavell D J, Wright D H. Tissue reactivity of a monoclonal antibody directed against cells of the human monocyte-macrophage lineage in formalin fixed paraffin embedded tissue. In: McMichael A, Hogg N, Horton M, eds. Leucocyte typing III. Oxford: Oxford University Press, 1987; 692-4.

13 Isaacson P, Jones D B, Millward-Sadler G H, Judd M A. Payne S. Alpha-1-antitrypsin in human macrophages. J Clin Pathol 1981: 34: $982-90$.

14 Mason D Y, Taylor C R. The distribution of muramidase (lysozyme) in human tissues. J Clin Pathol 1975; 28: 124-32.

15 Burmester G R, Dimitriu-Bona A. Waters S J, Winchester A J. Identification of three major synovial lining cell populations by monoclonal antibodies directed to Ia antigens and antigens associated with monocytes/macrophages and fibroblasts. Scand J Immunol 1983: 17: 69-82.

16 Duke O, Panayi G S. Janossy G, Poulter L W. An immunohistological analysis of lymphocyte subpopulations and their microenvironment in the synovial membranes of patients with rheumatoid arthritis using monoclonal antibodies. Clin Exp Immunol 1982; 49: 22-30.

17 Palmer D G, Selvendron Y. Allen C, Revell P A. Hogg N. Features of synovial membrane identified with moneclonal antibodies. Clin Exp Immunol 1985; 59: 529-38.

18 Meijer C J L M, van de Putte L B A, Euderlink F, et al. Characteristics of mononuclear cell populations in chronically inflamed synovial membranes. $J$ Pathol 1977; 121: 1-8.

19 Dayer J M, Passwell J H, Schneeberger E E, Krane S M. Interactions among rheumatoid synovial cells and monocytemacrophages: production of collagenase-stimulating factor by human monocytes exposed to concanavalin A or immunoglobulin Fc fragments. J Immunol 1980; 124: 1712-20.

20 Henderson B, Petipher E R. The synovial lining cell: biology and pathobiology. Semin Arthritis Rheum 1985; 15: 1-32.

21 Barratt M E J, Fell H B, Coombs R A A. Cilabert A M. The pig synovium. Il. Some properties of isolated intimal cells. $J$ Anat 1977; 123: 47-66.

22 Edwards J C W, Willoughby D A. Demonstration of bone marrow derived cells in synovial lining by means of giant intracellular granules as genetic marker. Ann Rheum Dis 1982; 41: $177-82$.

23 Espinoza L R. Rheumatoid arthritis: etiopathogenetic considerations. Clin Lab Med 1986; 6: 27-40.

24 Janossy G, Duke O. Poulter L W, Panayi G, Boyill M, Goldstein G. Rheumatoid arthritis: a disease of T-lymphocyte/ macrophage immunoregulation. Lancet 1981; ii: 839-42.

25 Poulter L W, Duke O. Hobbs S. Janossy G, Panayi G, Seymour G. The involvement of interdigitating (antigen-presenting) cells in the pathogenesis of rheumatoid arthritis. Clin Exp Immunol 1983; 51: 247-54.

26 Panayi G S. The aetiopathogenesis of rheumatoid arthritis. In: Scott J T, ed. Copeman's textbook of the rheumatic diseases. Edinburgh: Churchill Livingstone, 1986; 595-603. 